\title{
IL-26 in the induced sputum is associated with the level of systemic inflammation, lung functions and body weight in COPD patients
}

This article was published in the following Dove Press journal: International Journal of COPD

\author{
Lesia Savchenko' \\ Marina Mykytiuk' \\ Mathieu Cinato 2,3 \\ Helene Tronchere ${ }^{2,3}$ \\ Oxana Kunduzova ${ }^{2,3}$ \\ Igor Kaidashev'
}

'Ukrainian Medical Stomatological Academy, Poltava, Ukraine; ${ }^{2}$ National Institute of Health and Medical Research (INSERM) UI048, Toulouse, France; ${ }^{3}$ Department of Internal Medicine, University of Toulouse, UPS, Institute of Metabolic and Cardiovascular Diseases, Toulouse, France
Correspondence: Igor Kaidashev Department of Internal Medicine, Ukrainian Medical Stomatological Academy, Shevchenko Street, 23, 360II Poltava, Ukraine Email kaydashevip@gmail.com
Background: Chronic inflammatory process is the main link in COPD pathogenesis, which causes structural changes in the respiratory tract and lungs. In overweight patients, an adipose tissue could contribute to activation of the inflammatory process. Therefore, it is highly important to identify potential biomarkers of inflammation for patients with COPD and obesity. The aim of this study was to investigate the role of interleukin-26 (IL-26) and evaluate the relationship between the level of systemic inflammation, lung function, and body mass index (BMI) in patients with COPD.

Patients and methods: Eighty-three patients with COPD in the stable condition (stage 2 according to the 2016 Global Initiative for Chronic Obstructive Lung Disease recommendations), aged 40-70 years, were included in the study. All patients were divided into 2 groups: obese $(\mathrm{n}=53)\left(\mathrm{BMI}-30.0-39.9 \mathrm{~kg} / \mathrm{m}^{2}\right)$ and non-obese $(\mathrm{n}=30)\left(\mathrm{BMI}-18.5-24.9 \mathrm{~kg} / \mathrm{m}^{2}\right) . \mathrm{We}$ conducted patients' examination, spirometry, induced the sputum, determined the level of C-reactive protein (CRP), leptin in serum and IL-26 in sputum.

Results: Obese and non-obese COPD patients had a significant increase in IL-26 compared with healthy subjects by 2.3 and $2.6(P=0.0003)$. We also observed a higher level of CRP by 1.38 times $(P=0.0008)$, compared with the rate in non-obese COPD patients, and by 1.8 times $(P=0.015)$ higher concentration level of leptin compared with healthy subjects. The sputum IL-26 level had positive correlation with BMI, CRP, and leptin, and a negative - with forced expiratory volume in 1 second $\left(\mathrm{FEV}_{1}\right)$ and $\mathrm{FEV}_{1}$ /forced vital capacity. Leptin level had positive correlation with BMI and CRP, and negative with $\mathrm{FEV}_{1}, \mathrm{FEV}_{1} /$ forced vital capacity.

Conclusion: Obese COPD patients had a higher level of persistent systemic inflammation than non-obese ones, which is confirmed by a significant increase of CRP and leptin in serum. The data confirm that IL-26 can be considered as a perspective marker to detect the inflammation level in lung tissue of COPD patients.

Keywords: COPD, obesity, interleukin-26, induced sputum

\section{Introduction}

COPD and obesity are 2 mutually aggravating conditions, which have a common link in the pathogenesis - chronic systemic inflammation. ${ }^{1-3}$ The source of the latter in COPD patients is the lung tissue - bronchial tubes, and in obesity - adipose tissue. Given this, it is necessary to look for biomarkers of inflammation from the point of view of precision medicine for patients with COPD and obesity. C-reactive protein (CRP) and leptin are the common biomarkers of systemic inflammation, which can be used for estimation of the severity of COPD and obesity. ${ }^{4-6}$

One of the most promising biomarkers can be interleukin-26 (IL-26), which belongs to the family of cytokine IL-10. This IL is synthesized by T-cells in the 
lung and detected in small mononuclear cells of the alveoli, colocalized with transcription factor RHRCvar2 archetype Th 17 . The proinflammatory role of IL-26 has been studied in such chronic inflammatory disorders as rheumatoid arthritis, Crohn's disease, nonspecific ulcerative colitis, ${ }^{7,8}$ asthma, and antibacterial host defense of human lung. ${ }^{9,10}$ Considering the fact that a large number of proinflammatory cytokines that take part in the inflammatory process, the biological role and pathways of IL-26 expression remains insufficiently studied. Interacting with deoxyribonucleic acid (DNA) IL-26 promotes the secretion of interferon $-\alpha$ (IFN- $\alpha$ ) via toll-like receptor 9 (TLR9), promotes induction of IL-8 and / or IL-10 by some epithelial cell lines human via the receptors IL-20R1 and IL-10R2, provokes the synthesis of proinflammatory cytokines by myeloid cells and natural killer (NK-cells) of a person in the absence of IL-20R1. This suggested that IL-26 is not a classic cytokine. ${ }^{11,12}$ However, the role of IL-26 in the activation of lung and systemic inflammation in patients with COPD and overweight remains understudied.

\section{Patients and methods}

\section{Significance of study}

The aim of this study was to investigate the role of IL-26 and evaluate the relationship between the level of systemic inflammation, lung function, and body mass index (BMI) in patients with COPD.

\section{Subjects}

The study included 83 patients with COPD (B group according to the 2016 Global Initiative for Chronic Obstructive Lung Disease (GOLD) recommendations) over the period of 20162017. Inclusion criteria: male or female adults aged 40-70 years, with a diagnosis of COPD at least 12 months before the screening visit. Current smokers with a smoking habit history at least 10 pack-years. COPD was diagnosed according to the GOLD criteria, ${ }^{13}$ which included post-bronchodilator spirometry to confirm airflow obstruction (forced expiratory volume in 1 second/forced vital capacity $\left[\mathrm{FEV}_{1} / \mathrm{FVC}\right]$ ratio $<70 \%$, clinical signs: dyspnea, chronic cough or sputum production, and a history of exposure to risk factors for the disease). The included patients were in stable condition and had neither exacerbations (purulent sputum or high temperature) nor viral infections for at least 2 weeks prior to the study.

We excluded patients with asthma, conditions that were associated with inflammation, such as infection (by conducting complete blood count and biochemical blood analysis), cancer, significant cardiovascular conditions, such as unstable ischemic heart disease, New York Heart Association Class III/IV, acute myocardial infarction, uncontrolled endocrine disease (diabetes mellitus, morbid obesity [BMI $\left.>40 \mathrm{~kg} / \mathrm{m}^{2}\right]$ ), significant hepatic, renal, gastrointestinal impairments, and patients who were taking systemic corticosteroids.

All subjects underwent treatment according to the GOLD recommendation (fenoterol/ipratropium bromide 50/20) (Boehringer Ingelheim, Ingelheim am Rhein, Germany) t.i.d at least 2 weeks prior to the study.

According to BMI of COPD patients, they were divided into 2 groups: obese $(\mathrm{n}=53)\left(\mathrm{BMI}-30.0-39.9 \mathrm{~kg} / \mathrm{m}^{2}\right)$ and non-obese $(n=30)\left(B M I-18.5-24.9 \mathrm{~kg} / \mathrm{m}^{2}\right)$. Seventeen subjects with normal lung function and BMI formed the group of healthy subjects.

Due to the lack of compliance with taking induced sputum from patients, we analyzed the IL-26 and leptin concentrations only in 58 patients ( 31 obese COPD and 17 non-obese COPD patients, and 10 healthy subjects).

\section{Ethics statement}

The study was approved by the ethics committee of Ukrainian Medical Stomatological Academy. All patients signed a written informed consent form.

\section{Assessments and study procedures}

During the visit (at $17 \pm 3$ days after screening), patients' examination, spirometry with bronchodilator reversibility test were conducted, the sputum was induced, and the blood samples were collected.

Patients' examination included general clinical methods and measurement of anthropometric indices (BMI). BMI was calculated as weight $(\mathrm{kg}) /$ height $(\mathrm{m})^{2}$.

\section{Spirometry}

All subjects underwent spirometry (using Vitalograph, Clare, Ireland) in compliance with the American Thoracic Society and the European Respiratory Society guidelines; the bronchodilator reversibility test was conducted with subsequent evaluation of $\mathrm{FEV}_{1}, \mathrm{FEV}_{1} / \mathrm{FVC}^{14}$

\section{Sputum induction}

Before initiating the procedure, to prevent bronchospasm, the patients received salbutamol (Glaxo Wellcome Production, Mayenne, France) through a metered-dose inhaler at a dose of $400 \mu \mathrm{g}$ for 20 minutes. To induce the sputum, CN-02 My-Ulaizer Home nebulizer (Yuria-Pharm, Kyiv, Ukraine) was used. Inhalation was initiated with administration of $3 \%$ hypertonic solution (at a dose of $5.0 \mathrm{~mL}$ ), and after every 5-7 minutes of an inhalation, the concentration of hypertonic solution was increased by $1 \%$, successively using $3 \%, 4 \%$, 
and 5\% saline solution, respectively. After each session of inhalation, patients were offered to rinse mouth and throat thoroughly, to cough out the lower respiratory sputum in a special dish. When a satisfactory sample of sputum was obtained, the procedure was discontinued. Then the sputum was centrifuged and the supernatant was stored at $-70^{\circ} \mathrm{C}$ until analysis. The level of IL-26 protein concentrations (pg/mL) was measured using the enzyme linked immunosorbent assay kit (RayBiotech ${ }^{\circledR}$ ) according to the instructions. The minimum detectable dose was $3.3 \mathrm{pg} / \mathrm{mL}$.

\section{Serum measurements}

Serum levels of CRP and leptin were measured using the "Vector-Best" reagents (Russian Federation) and immunoassay kit (SPI-Bio, Montigny le Bretonneux, France), respectively, according to the manufacturers' instructions.

\section{Statistics}

Data are expressed as mean \pm SEM. Statistical comparison between 2 groups was analyzed using analysis of variance (non-parametric) test with Kruskal-Wallis test, accompanied by Mann-Whitney rank-sum test. Spearman test was used for correlating non-parametric variables. We used GraphPad Prism version 5.00 (GraphPad Software, Inc., San Diego, CA, USA). Probability of $P<0.05$ was considered statistically significant.

\section{Results}

\section{Characteristics of patients}

According to the BMIs, all COPD patients were divided into 2 groups: obese $(n=53)$ and non-obese $(n=30)$. Patients' demographic information is summarized in Table 1.
The groups of patients were comparable in terms of age and gender with predominance of male ratio, and pack-years. Body weight and BMI were higher and spirometric indices were lower $\left(\mathrm{FEV}_{1}, \mathrm{FEV}_{1} / \mathrm{FVC}\right)$ in obese COPD patients $(P<0.05)$ (Table 1).

\section{IL-26 concentration in the induced sputum}

The IL-26 level concentration in the induced sputum was evaluated only in 58 patients. Non-obese COPD patients had higher concentration level of IL-26 in the induced sputum by 2.3 times compared with healthy subjects $\left(120.6 \pm 60 .{ }^{15} \mathrm{pg} / \mathrm{mL}\right.$ against $\left.53.15 \pm 18.5 \mathrm{pg} / \mathrm{mL}\right)(P=0.0003)$. Obese COPD patients had a significant increase in the concentration of IL-26 compared with healthy subjects by 2.6 $(139.0 \pm 85.4 \mathrm{pg} / \mathrm{mL}$ against $53.15 \pm 18.5 \mathrm{pg} / \mathrm{mL})(P<0.0001)$, (Figure 1A).

\section{Markers of systemic inflammation}

Compared with CRP concentration in sera of healthy subjects, we found its increase by 5.6 times $(P<0.0001)$ in non-obese COPD patients and by 7.8 times $(P<0.0001)$ in obese COPD patients. It should be noted that obese COPD patients had by 1.38 times higher level of CRP $(8.79 \pm 3.94 \mathrm{IU} / \mathrm{L}$ against $6.35 \pm 3.03 \mathrm{IU} / \mathrm{L})(P=0.0008)$, compared with the rate in nonobese COPD patients (Figure 1B).

The leptin level concentration in sera was also evaluated in 58 patients. We found that obese COPD patients had a higher concentration level than healthy subjects by 1.8 times $(P=0.015)(34.03 \pm 18.5 \mathrm{ng} / \mathrm{mL}$ against $18.3 \pm 15.4 \mathrm{ng} / \mathrm{mL}) . \mathrm{In}$ non-obese COPD patients, this marker was not significantly different from healthy subjects (Figure 1C).

Table I Characteristics of the studied population

\begin{tabular}{|c|c|c|c|c|}
\hline Characteristics & $\begin{array}{l}\text { Healthy } \\
\text { subjects }(n=17)\end{array}$ & $\begin{array}{l}\text { Non-obese COPD } \\
\text { patients }(n=30)\end{array}$ & $\begin{array}{l}\text { Obese COPD } \\
\text { patients }(n=53)\end{array}$ & $P$-value \\
\hline Age, years & $52.65 \pm 8.68$ & $57.17 \pm 8.27$ & $56.75 \pm 7.58$ & ns \\
\hline Male/female (n) & $10 / 7$ & $23 / 7$ & $38 / 15$ & ns \\
\hline \multirow[t]{2}{*}{ Weight, kg } & $66.76 \pm 6.37$ & $68.11 \pm 6.68$ & $96.30 \pm 9.41$ & $0.000 I^{*}$ \\
\hline & & & & $0.0001 * *$ \\
\hline Height, m & $1.72 \pm 0.05$ & $1.72 \pm 0.06$ & I. $70 \pm 0.08$ & ns \\
\hline \multirow[t]{2}{*}{$\mathrm{BMI}, \mathrm{kg} / \mathrm{m}^{2}$} & $22.63 \pm 1.45$ & $23.08 \pm 1.32$ & $33.48 \pm 2.5$ & $0.000 I^{*}$ \\
\hline & & & & $0.000 I * *$ \\
\hline Pack-years & - & $24.05 \pm 6.76$ & $21.72 \pm 7.11$ & ns \\
\hline \multirow[t]{2}{*}{$\mathrm{FEV}_{1}, \%$} & $81.93 \pm 5.24$ & $63.10 \pm 3.61^{*}$ & $59.11 \pm 4.77$ & $0.0001 *$ \\
\hline & & & & $0.000 I^{* *}$ \\
\hline \multirow[t]{2}{*}{$\mathrm{FEV}_{1} / \mathrm{FVC}, \%$} & $78.7 I \pm 5.29$ & $66.67 \pm 2.35^{*}$ & $62.47 \pm 3.85$ & $0.0001 *$ \\
\hline & & & & $0.000 I^{* *}$ \\
\hline
\end{tabular}

Notes: Data are presented as mean \pm SD. *Difference between healthy patients and patients with COPD; **difference between non-obese and obese COPD patients. Abbreviations: BMI, body mass index; FEV , forced expiratory volume in I second; FVC, forced vital capacity; ns, not significant. 

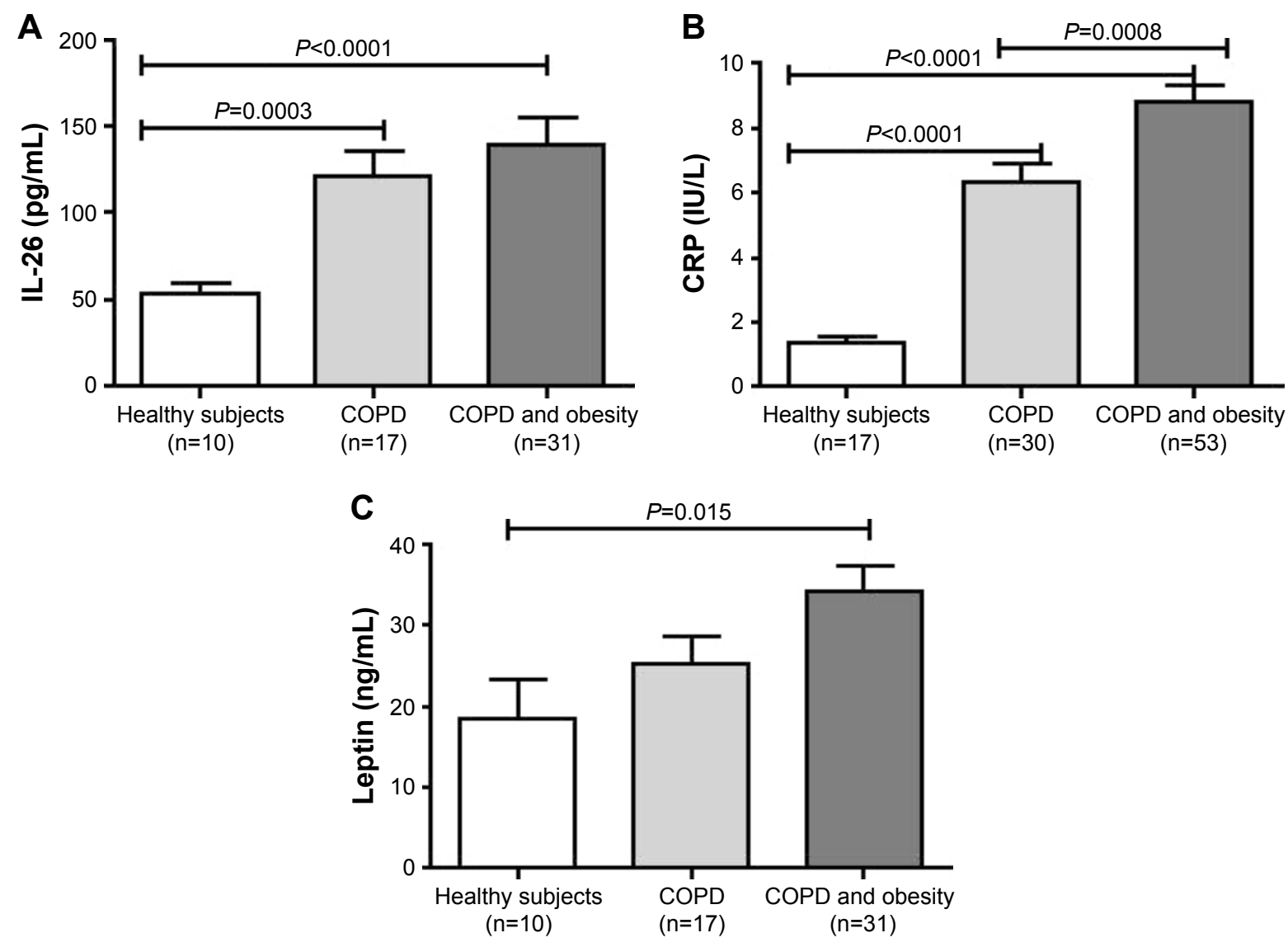

Figure I Biomarkers concentration in the biological fluids from populations investigated: (A) IL-26 in induced sputum; (B) CRP level in serum; (C) leptin level in serum. Abbreviations: CRP, C-reactive protein; IL, interleukin.

\section{Cytokines concentrations and correlations with $\mathrm{BMI}$ and some spirometric indices}

We found a positive correlation between sputum IL-26 level and BMI $(R=0.49 ; P<0.0001)$ (Figure 2A), serum CRP level $(R=0.60 ; P<0.0001)$ (Figure 2D) and leptin level $(R=0.57 ; P<0.0001)$ (Figure 2E). Serum CRP level was correlated with BMI $(R=0.57 ; P<0.0001)$ (Figure $2 \mathrm{~B})$. Serum leptin level was correlated with BMI $(R=0.55 ; P<0.0001)$ (Figure $2 \mathrm{C})$ and serum CRP level $(R=0.57 ; P<0.0001)$ (Figure 2F).

Given the importance of spirometry parameters $\left(\mathrm{FEV}_{1}\right.$, $\mathrm{FEV}_{1} / \mathrm{FVC}$ ), we conducted a correlation analysis between these indicators and inflammation markers to determine the severity of COPD. The results of the study show an inverse correlation between sputum IL-26 level and $\mathrm{FEV}_{1}(R=-0.65$; $P<0.0001)$ (Figure 3A), $\mathrm{FEV}_{1} / \mathrm{FVC}(R=-0.38 ; P=0.003)$, respectively (Figure 3D).

We found a significant negative correlation between serum CRP level and $\mathrm{FEV}_{1}(R=-0.58 ; P<0.0001)$ (Figure 3B), $\mathrm{FEV}_{1} / \mathrm{FVC}(R=-0.54 ; P<0.0001)$ (Figure $\left.3 \mathrm{E}\right)$.
A significant negative correlation was found between serum leptin level and $\mathrm{FEV}_{1}(R=-0.59 ; P<0.0001)$ (Figure $3 \mathrm{C}), \mathrm{FEV}_{1} / \mathrm{FVC}(R=-0.34 ; P=0.001)$, respectively (Figure 3F).

\section{Discussion}

Chronic inflammatory process in the lower respiratory tract and lung in patients with stable COPD is associated with increased expression of cytokines, including tumor necrosis factor-alpha (TNF- $\alpha$ ), interferon-gamma, IL-1 $\beta$, IL-6, IL-17, IL-18, IL-32, thymic stromal lymphopoietin, and growth factors, such as transforming growth factor-beta. ${ }^{15}$ It has been suggested that Th17 cells actively participate in antibacterial protection in the pulmonary tissue, contributing to the accumulation of neutrophils and macrophages in inflammation. The study of the role of IL-26 in the development and persistence of inflammatory process in different diseases is a major focus of researchers' interest. IL-26 is classified as a member of the IL-10 family of cytokines because it has a limited sequence homology to IL-10 and IL-10-linked cytokines. IL-26 often coexists with IL-22 activated by 

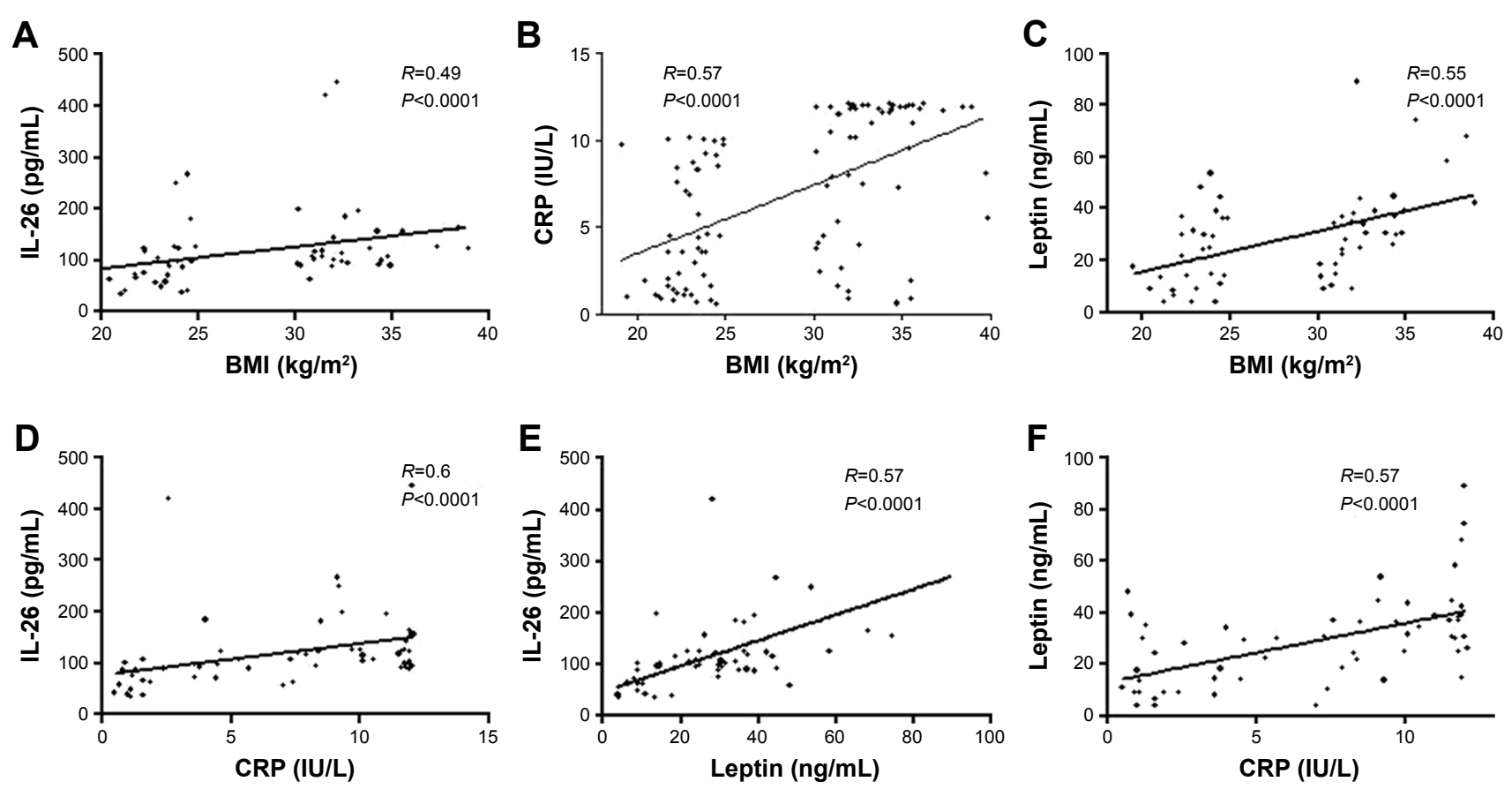

Figure 2 Correlation analysis (A) IL-26 with BMI; (B) CRP with BMI; (C) leptin with BMI; (D) IL-26 with CRP; (E) IL-26 with leptin; (F) leptin with CRP. Abbreviations: BMI, body mass index; CRP, C-reactive protein; IL, interleukin.

T-cells, especially Th17 cells. It is manifested through the heterodimeric receptor complex consisting of the IL-20R1 and IL-10R2 chains. IL-26 receptors are primarily located in non-hematopoietic and epithelial cells. ${ }^{16,17}$

Recent studies have shown that extracellular IL-26 was found in bronchoalveolar lavage (BAL) specimens without prior in vivo exposure and was markedly elevated after exposure to endotoxins. Recombinant IL-26 potentiated neutrophil chemotaxis, induced by IL-8 and fMLP. The IL-26 receptor complex was detected in neutrophils, and IL-26 decreased the activity of STAT3 phosphorylation in these cells. Finally, IL-26 increased the release of
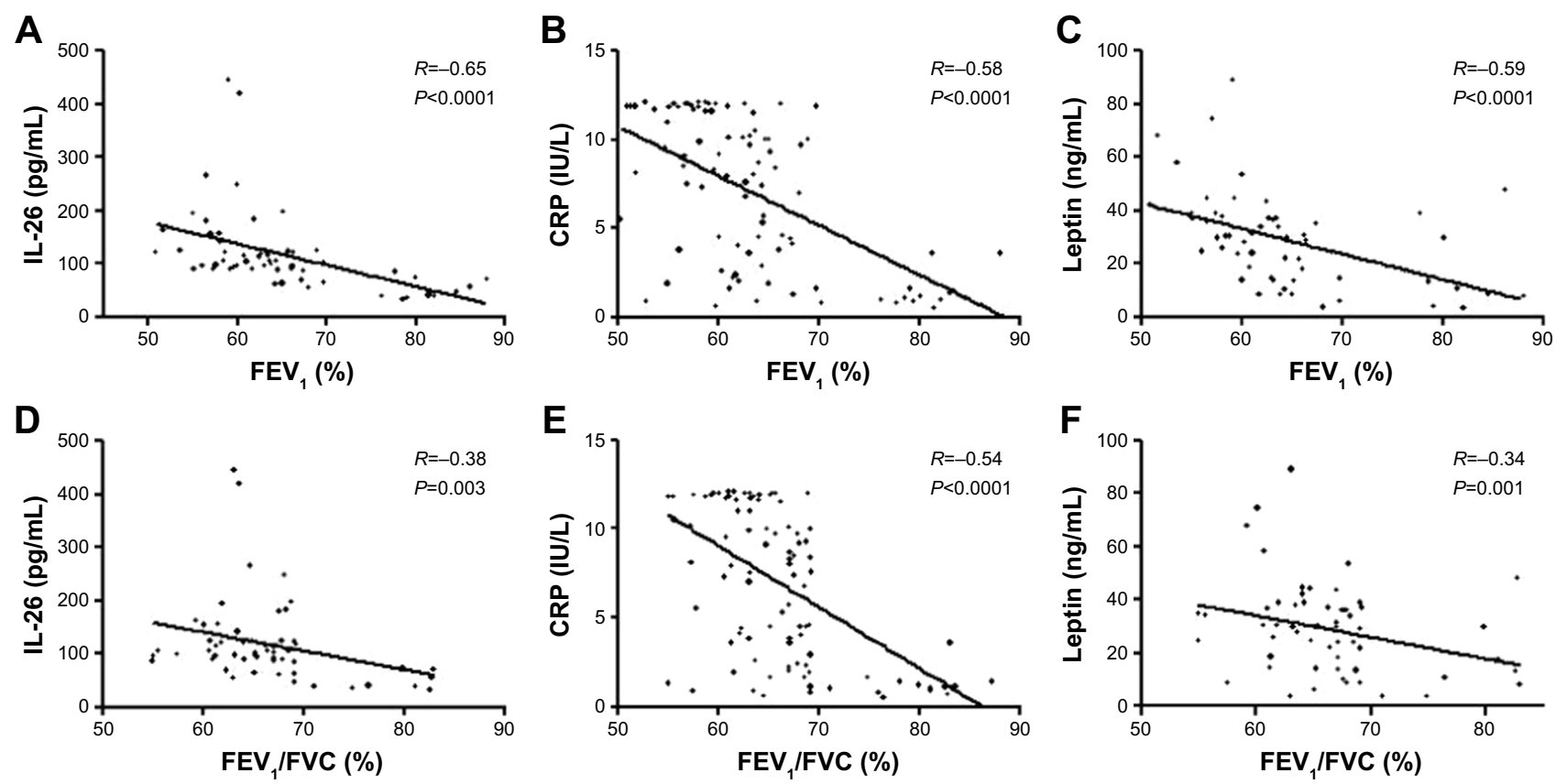

Figure 3 Correlation analysis (A) IL-26 with FEV ; (B) CRP with FEV; (C) leptin with FEV ; (D) IL-26 with FEV /FEV; (E) CRP with FEV /FVC; (F) leptin with FEV,/FEV. Abbreviations: CRP, C-reactive protein; $\mathrm{FEV}_{1}$, forced expiratory volume in I second; FVC, forced vital capacity; IL, interleukin. 
neutrophil mobilizing cytokines in BAL, but not in the epithelial cells. ${ }^{10}$.

It was shown that $\mathrm{FEV}_{1}$ and $\mathrm{FEV}_{1} / \mathrm{FVC}$ decreased in overweight patients. The evaluation data of external respiratory function show a potential decrease of $\mathrm{FEV}_{1}$ and $\mathrm{FEV}_{1} /$ FVC in overweight patients. Furthermore, the association between increased $\mathrm{BMI}$ and reduction of $\mathrm{FEV}_{1}$ is stronger than $\mathrm{FEV}_{1} / \mathrm{FVC}^{2}$.

Assessment of the spirometry indices dynamics is an important aspect of studying the role of IL-26 in the progression of COPD combined with obesity.

Our study found that obese COPD patients had significantly higher IL-26 concentration level in the induced sputum than healthy subjects. There were no differences between obese and non-obese COPD patients. Correlation analysis showed a relationship between sputum IL-26 and serum levels of CRP, leptin, thus confirming the pathogenetic mechanisms of systemic inflammation. We established that sputum IL-26 level negatively correlated with FEV $_{1}$ and $\mathrm{FEV}_{1} / \mathrm{FVC}$. The obtained data might confirm the idea about the important role of IL-26 in progressing COPD.

CRP is a high-sensitivity marker for disorders of energy metabolism, functional capacity, and severity of COPD symptoms. Increased CRP in patients with COPD is an adverse prognostic factor for the progression of bronchial obstruction and development of respiratory failure. ${ }^{4}$ In our research, we found that the concentration level of CRP was higher by 5.6 times $(P<0.0001)$ in non-obese COPD patients and 7.8 times $(P<0.0001)$ in obese COPD ones compared with healthy subjects.

Leptin is a hormone, which is synthesized by adipocytes, and reveals pleiotropic functions in both congenital and acquired immunity. Recent studies have shown that leptin is secreted not only by adipocytes but by various epithelial cell types (intestinal, gastric, mammary, and bronchial epithelial cells, and type II pneumocytes). A previous study showed that leptin protein is found in the induced sputum, proximal airway biopsies, BAL, and peripheral lung tissue. ${ }^{5,6}$ It was shown that leptin correlates with $\mathrm{BMI}, \mathrm{FEV}_{1} / \mathrm{FVC}$ and is higher in obese subjects. ${ }^{6}$ Taken together, these data suggest that leptin plays an important role in the development of respiratory immune responses and additionally in the pathogenesis of inflammatory respiratory diseases. ${ }^{5}$

Our data go in parallel with these results, since obese COPD patients had significantly higher serum leptin level than healthy subjects. Correlation analysis performed in these patients had shown correlation between serum leptin level and BMI, CRP, FEV , FEV $_{1} / \mathrm{FVC}$.
The results of meta-analysis of leptin concentration in patients with COPD suggest that BMI and gender of patients were the dominant determinants for increased leptin concentrations in COPD patients in the remission period. Meanwhile the correlation between BMI and serum leptin level was generally weaker with acute exacerbations compared with stable phase. ${ }^{18}$

In COPD patients, both BMI and the fat-free mass index (FFMI) showed significant positive and negative associations in terms of leptin level, while the FFMI represented an additional negative association with TNF- $\alpha$ level. Both BODE (Body mass index, airflow Obstruction, Dyspnea, and Exercise capacity) and FFMI are associated with circulating level of leptin in COPD patients, indicating a possible role of leptin in the systemic component of COPD. ${ }^{3}$

Thus, the obtained results proved the additional negative effect of leptin on the course of COPD in obese patients.

\section{Limitations}

Our study had some limitations. Due to the lack of compliance with taking induced sputum from patients, we analyzed IL-26 and leptin concentrations only in 48 COPD patients and 10 healthy subjects. A stronger calculation could be performed for statistical analysis to ensure the significance of differences in sputum IL-26 concentration between obese and non-obese COPD patients.

\section{Conclusion}

The level of IL-26 in the induced sputum was higher in obese COPD patients than in healthy subjects. There were no differences between obese and non-obese COPD patients.

Obese COPD patients had higher level of persistent systemic inflammation than non-obese COPD ones and healthy subjects, which is confirmed by significant increase in serum CRP and leptin. Correlation analysis showed relationship between sputum IL-26 and serum levels of CRP and leptin, thus confirming the pathogenetic mechanisms of systemic inflammation. We established that sputum IL-26 level negatively correlated with $\mathrm{FEV}_{1}$ and $\mathrm{FEV}_{1} / \mathrm{FVC}$. The obtained data might confirm the idea that sputum IL-26 can be considered as a perspective marker to detect inflammation in the lung tissue of COPD patients.

\section{Acknowledgments}

This work was supported by Ukrainian Medical Stomatological Academy, Poltava, Ukraine ("Comprehensive study of the pathogenetic role of the subpopulation of macrophages M1 and M2 in the development of COPD for the reasoning 
and substantiation of personalized therapy based on body weight", Fundamental research project, State registration No. 0117U005252, Ukrainian Ministry of Health Public Service) and by University of Toulouse, France; Institute of Metabolic and Cardiovascular Diseases, Toulouse, France, and ERASMUS + project.

\section{Disclosure}

The authors report no conflicts of interest in this work.

\section{References}

1. Cazzola M, Novelli G. Biomarkers in COPD. Pulm Pharmacol Ther. 2010;23(6):493-500.

2. Zammit $\mathrm{C}$, Liddicoat $\mathrm{H}$, Moonsie I, Makker H. Obesity and respiratory diseases. Int J Gen Med. 2010;3:335-343.

3. Gaki E, Kontogianni K, Papaioannou AI, et al. Associations between BODE index and systemic inflammatory biomarkers in COPD. COPD. 2011;8(6):408-413.

4. Dahl M. C-reactive protein is a strong predictor of prognosis in COPD. Respir Med. 2007;3(4):122.

5. Vernooy JH, Drummen NE, van Suylen RJ, et al. Enhanced pulmonary leptin expression in patients with severe COPD and asymptomatic smokers. Thorax. 2009;64(1):26-32.

6. Bruno A, Alessi M, Soresi S, et al. Increased leptin/leptin receptor pathway affects systemic and airway inflammation in COPD former smokers. J Inflamm Res. 2011;4:51-59.

7. Corvaisier M, Delneste Y, Jeanvoine H, et al. IL-26 is overexpressed in rheumatoid arthritis and induces proinflammatory cytokine production and Th17 cell generation. PLoS Biol. 2012;10(9):e1001395.
8. Dambacher J, Beigel F, Zitzmann K, et al. The role of the novel Th17 cytokine IL-26 in intestinal inflammation. Gut. 2009;58(9): 1207-1217.

9. Konradsen JR, Nordlund B, Levänen B, Hedlin G, Linden A. The cytokine interleukin-26 as a biomarker in pediatric asthma. Respir Res. 2016;17:32.

10. Che KF, Tengvall S, Levänen B, et al. Interleukin-26 in antibacterial host defense of human lungs. Effects on neutrophil mobilization. Am J Respir Crit Care Med. 2014;190(9):1022-1031.

11. Meller S, di Domizio J, Voo KS, Voo HC, et al. T(H)17 cells promote microbial killing and innate immune sensing of DNA via interleukin 26 Nat Immunol. 2015;16(9):970-979.

12. Miot C, Beaumont E, Duluc D, et al. IL-26 is overexpressed in chronically HCV-infected patients and enhances TRAIL-mediated cytotoxicity and interferon production by human NK cells. Gut. 2015; 64(9):1466-1475.

13. Global Initiative for Chronic Obstructive Lung Disease (GOLD). Pocket guide to COPD diagnosis, management, and prevention 2017; 2017. Available from: http://www.goldcopd.org. Accessed December 13, 2017.

14. Miller MR, Hankinson J, Brusasco V, et al. ATS/ERS Task Force Standardisation of spirometry. Eur Respir J. 2005;26(2):319-338.

15. Caramori G, Casolari P, Barczyk A, Durham AL, di Stefano A, Adcock I. COPD immunopathology. Semin Immunopathol. 2016;38(4): 497-515.

16. Donnelly RP, Sheikh F, Dickensheets H, et al. Interleukin-26: an IL-10related cytokine produced by Th17 cells. Cytokine Growth Factor Rev. 2010;21(5):393-401.

17. Mukherjee S, Lindell DM, Berlin AA, et al. IL-17-induced pulmonary pathogenesis during respiratory viral infection and exacerbation of allergic disease. Am J Pathol. 2011;179(1):248-258.

18. Zhou L, Yuan C, Zhang J, et al. Circulating leptin concentrations in patients with chronic obstructive pulmonary disease: a systematic review and meta-analysis. Respiration. 2013;86(6):512-522.
International Journal of COPD

\section{Publish your work in this journal}

The International Journal of COPD is an international, peer-reviewed journal of therapeutics and pharmacology focusing on concise rapid reporting of clinical studies and reviews in COPD. Special focus is given to the pathophysiological processes underlying the disease, intervention programs, patient focused education, and self management protocols.

\section{Dovepress}

This journal is indexed on PubMed Central, MedLine and CAS. The manuscript management system is completely online and includes a very quick and fair peer-review system, which is all easy to use. Visit http://www.dovepress.com/testimonials.php to read real quotes from published authors. 